\title{
Clinic and ambulatory heart rates in patients with ischaemic heart disease and/or chronic heart failure taking rate-limiting medications: are they interchangeable?
}

\author{
Omar Javed, ${ }^{1}$ Kenneth Koo, ${ }^{1}$ Omar El-Omar, ${ }^{1}$ Stuart Allen, ${ }^{2}$ Alexander Squires, ${ }^{3}$ \\ Magdi El-Omar ${ }^{1,2}$
}

${ }^{1}$ Manchester Medical School, The University of Manchester, Manchester, UK

${ }^{2}$ Department of Cardiology, Manchester Heart Centre, Manchester Royal Infirmary, Manchester, UK

${ }^{3}$ School of Social Sciences, The University of Manchester, Manchester, UK

\section{Correspondence to} Dr Magdi El-Omar, Department of Cardiology, Manchester Heart Centre, Manchester Royal Infirmary, Manchester M13 9WL, UK; magdi.el-omar@cmft.nhs.uk

Received 9 June 2014 Revised 4 November 2014 Accepted 8 November 2014 Published Online First 26 November 2014

\section{(a) CrossMark}

To cite: Javed 0 , Koo K, El-Omar 0 , et al. Postgrad Med J 2015;91:8-12.

\section{ABSTRACT \\ Background The prognostic benefit from heart rate (HR) reduction in patients with ischaemic heart disease (IHD) and/or chronic heart failure (CHF) is now firmly established. Most decisions regarding initiation and/or dose adjustment of HR-limiting medications in such patients are based on clinic HR. Yet, this is a highly variable parameter that may not necessarily reflect HR control over the $24 \mathrm{~h}$ period.}

Objective To examine the level of agreement between mean clinic and mean ambulatory HRs in patients with IHD and/or CHF taking rate-limiting medications.

Methods Prospective, observational study. Fifty patients with IHD and/or CHF who attended cardiology outpatient clinics at the Manchester Heart Centre and underwent same-day $24 \mathrm{~h}$ continuous ECG recording between March and October 2013 were included in the study. Mean clinic HR was compared with mean $24 \mathrm{~h}$, daytime and night-time HRs. Limits-of-agreement plots were constructed to examine the relationship between the two HR measures in more detail.

Results The mean clinic HR was numerically similar to the mean HRs of all ambulatory time periods examined. However, on Bland-Altman plots, the limits of agreement between clinic and ambulatory HR means were quite wide, with the mean clinic HR ranging between 10.93 and 13.58 bpm below and 8.4 and $18.15 \mathrm{bpm}$ above the mean ambulatory HR.

Conclusions Although numerically similar, the means of clinic and ambulatory HRs in patients with IHD and/or CHF display wide limits of agreement. As such, the two measures cannot be regarded as interchangeable.

\section{INTRODUCTION}

Heart rate (HR) is a simple and readily accessible clinical variable which has been shown to predict adverse cardiovascular and non-cardiovascular events in apparently healthy individuals, ${ }^{1}{ }^{2}$ as well as patients with various cardiovascular conditions, including heart failure, ${ }^{3-5}$ stable coronary artery disease (CAD) ${ }^{6-8}$ acute coronary syndromes ${ }^{9}$ and hypertension. ${ }^{10}$ In general, the slower the HR, the better the prognosis. ${ }^{11-14}$ In a large French study of subjects undergoing routine health examinations, resting tachycardia was predictive of mortality independent of age and blood pressure. ${ }^{2}$ More recently, results from landmark studies such as BEAUTIFUL ${ }^{6}$ and SHIFT ${ }^{11}$ have highlighted the prognostic impact of elevated HR and the importance of HR reduction in patients with ischaemic heart disease
(IHD) and chronic heart failure (CHF), respectively. These results underscore the importance of working towards a well-defined target $\mathrm{HR}$ in patients with cardiovascular conditions, including IHD and $\mathrm{CHF}^{14}$

Most of the studies that have examined the prognostic impact of HR reduction on clinical outcomes have relied solely on clinic, rather than ambulatory, HR measures. ${ }^{15}$ Similarly, most recent guidelines on cardiovascular disease management advocate measurement of resting, rather than ambulatory, HR. ${ }^{16} 17$ The recent European Society of Cardiology guidelines on the management of stable CAD go a step further by highlighting the lack of good evidence to support routine use of ambulatory ECG monitoring as a tool for refined prognostication. ${ }^{18}$

However, clinic HR represents a 'snapshot' of a highly variable clinical parameter which is affected by multiple physical, environmental and psychological factors, leading to frequent short-term fluctuations. ${ }^{19}$ Since the aim of rate-limiting pharmacotherapy is to achieve HR control throughout the whole $24 \mathrm{~h}$ period, rather than focus on a specific time period during the day or night, a single HR measurement in an outpatient clinic may not be representative of HR control over a $24 \mathrm{~h}$ period, and may therefore be an inaccurate guide to therapeutic decisions relating to initiation and dose titration of ratelimiting medications. This raises the question of whether ambulatory, rather than clinic, HR measurements should be used as the basis for assessing HR control in day-to-day clinical practice, although adoption of such a strategy may be impractical, costly or simply unnecessary. ${ }^{20}$

The aim of this observational study was to assess the agreement between two different ways of measuring HR: resting HR, measured in an outpatient clinic setting, and mean ambulatory HR, derived from $24 \mathrm{~h}$ Holter (ECG) recordings. From this, we aim to provide an answer to the question of whether these two measurements can be used interchangeably for the assessment of HR control in patients with IHD and/or CHF taking rate-limiting medications.

\section{METHODS}

\section{Patients}

Patients were recruited from general cardiology, dedicated heart function or cardiac resynchronisation outpatient clinics at the Manchester Heart Centre, between March and October 2013. We 
included patients with a primary diagnosis of IHD and/or CHF of any aetiology who were in sinus rhythm and taking ratelimiting medications, such as $\beta$-blockers and/or ivabradine. Only patients who underwent $24 \mathrm{~h}$ Holter recording on the same day as their clinic appointment were included in the study. Indications for the Holter study included assessment of symptoms (eg, palpitations, dizziness, syncope), as a guide to dose adjustment of rate-limiting medications or simply to assess drug compliance where this was in question. Patients known to be in atrial fibrillation and those with permanent pacemakers but atrially sensing $<90 \%$ of the time were excluded. Any suggested alterations to drug regimen, including rate-limiting medications, were communicated to the patient's general practitioner for implementation. This process usually took in excess of 1 week. As such, there was no change to the dose or type of medication prescribed between the recordings of clinic and ambulatory HRs.

\section{Data collection}

Patients had their radial pulse measured for $30 \mathrm{~s}$ in a sitting position, at the beginning, middle and near the end of the outpatient clinic consultation. Measurements were made by University of Manchester medical students (OJ, KK and OE-O) or qualified doctors in attendance at these clinics. The values were then multiplied by 2 to obtain the number of beats per minute (bpm). Immediately after the clinic consultation, medical students escorted patients to the ECG department where they were fitted with a $24 \mathrm{~h}$ Holter tape (Spacelabs Healthcare). The tapes were returned the next day and analysed by a team of cardiac physiologists at the Manchester Heart Centre. Patient demographics and other relevant clinical details were extracted from the case notes as well as patient electronic records.

\section{DATA ANALYSIS}

For each patient, we calculated the mean of the three clinic HRs, as well as the minimum, maximum and mean daytime (07:00-23:00), working hours (09:00-17:00), night-time (23:00-07:00) and $24 \mathrm{~h}$ HR from the $24 \mathrm{~h}$ Holter recordings. The 09:00-17:00 time period was included as it represents a time when most outpatient clinics tend to run in UK clinical practice. Differences between the means were examined using the paired $\mathrm{t}$ test, with $\mathrm{p}<0.05$ considered significant.

To examine the agreement, and therefore interchangeability, between the means of clinic and ambulatory HRs, we constructed limits-of-agreement plots (also known as Bland-Altman plots) for each of the comparisons. The limits of agreement estimate the approximate $95 \%$ CI for an individual predicted difference between two measurements (usually two SDs above or below). The wider the interval, the greater the variance between the two measurements, and therefore the less interchangeable they are.

StatsDirect software (V.2.7.9) was used for all statistical analyses.

\section{Ethics permission}

No ethics committee approval was sought for this study, which was purely observational and relied on analysis of data available from routine clinical investigations.

\section{RESULTS}

\section{Demographic and clinical data}

Fifty patients took part in this study. The mean \pm SD age was $61.8 \pm 12.3$ years and $68 \%$ were male. All patients had IHD and/or CHF, and $\sim 30 \%$ were diabetic. All patients were taking rate-limiting medications, most commonly bisoprolol (table 1).
Table 1 Description of patients

\begin{tabular}{|c|c|}
\hline Variable & Value $(\mathrm{N}=50)$ \\
\hline Age (years) & $61.8 \pm 12.3$ \\
\hline Male & $34(68)$ \\
\hline \multicolumn{2}{|l|}{ Ethnicity } \\
\hline Asian & $11(22)$ \\
\hline Black & $4(8)$ \\
\hline White & $32(64)$ \\
\hline Mixed race & $1(2)$ \\
\hline Other/unknown & $2(4)$ \\
\hline \multicolumn{2}{|l|}{ Smoking history } \\
\hline Current smoker & $6(12)$ \\
\hline Ex-smoker & $19(38)$ \\
\hline Never smoked & $25(50)$ \\
\hline Family history of IHD & $28(56)$ \\
\hline \multicolumn{2}{|l|}{ Medical history } \\
\hline Chronic kidney disease & $5(10)$ \\
\hline COPD & $4(8)$ \\
\hline Heart failure & $22(44)$ \\
\hline Hypertension & $27(54)$ \\
\hline IHD & $39(78)$ \\
\hline PE/DVT/CVD & 7 (14) \\
\hline Diabetes mellitus & $15(30)$ \\
\hline Thyroid disease & $6(12)$ \\
\hline Previous CABG & $16(32)$ \\
\hline Previous PCI & $23(46)$ \\
\hline ICD & $9(18)$ \\
\hline \multicolumn{2}{|l|}{ Medication } \\
\hline$\beta$-Blockers & $50(100)$ \\
\hline Atenolol & $3(6)$ \\
\hline Bisoprolol & $44(88)$ \\
\hline Carvedilol & $2(4)$ \\
\hline Nebivolol & $1(2)$ \\
\hline \multicolumn{2}{|l|}{ Other } \\
\hline ACE inhibitor & $38(76)$ \\
\hline Aspirin/warfarin & $45(90)$ \\
\hline Calcium channel blocker & $9(18)$ \\
\hline Clopidogrel/ticagrelor/prasugrel & $19(38)$ \\
\hline Diuretic & $29(58)$ \\
\hline Ivabradine & $1(2)$ \\
\hline Nitrate & $25(50)$ \\
\hline Statin & $40(80)$ \\
\hline
\end{tabular}

Values are mean $\pm \mathrm{SD}$ or number $(\%)$. CABG, coronary artery bypass graft surgery; COPD, chronic obstructive pulmonary disease; CVD, cerebrovascular disease; DVT, deep vein thrombosis; ICD, implantable cardioverter defibrillator; IHD, ischaemic heart disease; $\mathrm{PCl}$, percutaneous coronary intervention; $\mathrm{PE}$, pulmonary embolism.

\section{Clinic and ambulatory HRs}

The means of clinic and ambulatory HRs for the group as a whole were quite similar and relatively low $(<70 \mathrm{bpm})$, suggesting that the study patients were generally well treated with ratelimiting medications (table 2). However, when individual values are examined, wide differences are found between them (table 2).

\section{Limits of agreement between clinic and ambulatory HR means}

The mean clinic HR was slightly higher than the means of night-time and $24 \mathrm{~h} \mathrm{HR}$, but slightly lower than the means of daytime and 09:00-17:00 HR (table 3). There was no significant difference between the means of clinic and $24 \mathrm{~h} \mathrm{HR}$, while 
Table 2 Description of heart rate (bpm) measured at different times

\begin{tabular}{llll}
\hline & Mean (SD) & Lowest mean & Highest mean \\
\hline Clinic & $66.3(10.0)$ & 51 & 97 \\
24 h & $65.8(9.1)$ & 48 & 86 \\
09:00-17:00 & $69.4(10.3)$ & 48 & 97 \\
07:00-23:00 & $68.4(10.1)$ & 48 & 92 \\
23:00-07:00 & $62.9(9.5)$ & 43 & 85 \\
\hline
\end{tabular}

small but significant differences existed between the mean clinic $\mathrm{HR}$ and the mean HRs of all other time periods examined. In 11 patients, the means of clinic and $24 \mathrm{~h}$ HRs were $>70 \mathrm{bpm}$. Three patients had a mean clinic $\mathrm{HR}>70 \mathrm{bpm}$, but a mean $24 \mathrm{~h} \mathrm{HR} \leq 70 \mathrm{bpm}$, while five patients had a mean $24 \mathrm{~h} \mathrm{HR}$ $>70 \mathrm{bpm}$ but a mean clinic HR $\leq 70 \mathrm{bpm}$. Assuming a desirable target HR in these patients of $\leq 70 \mathrm{bpm}$, eight patients $(16 \%)$ showed incongruent results between clinic and $24 \mathrm{~h}$ ambulatory measurements.

The limits of agreement (the mean bias plus or minus two times the SD of differences) for all comparisons were quite wide (table 3). Thus, for instance, the $24 \mathrm{~h}$ mean HR may be up to $11.93 \mathrm{bpm}$ above or $10.93 \mathrm{bpm}$ below the mean clinic HR, with an 'interval' between the limits (a measure of variance) of $22.86 \mathrm{bpm}$. The 'intervals' for the other ambulatory time periods were similarly wide: 09:00-17:00 $=23.08 \mathrm{bpm}$; 07:00$23: 00=22.92 ; 23: 00-07: 00=29.42 \mathrm{bpm}$. As such, the $24 \mathrm{~h}$ mean HR shows the narrowest 'interval', and therefore least variance, with mean clinic HR, while the night-time mean HR shows the widest 'interval', and therefore most variance, with mean clinic HR.

An example of a Bland-Altman plot (clinic and $24 \mathrm{~h}$ ambulatory HRs), demonstrating wide limits of agreement between the means, is shown in figure 1.

\section{DISCUSSION}

In this observational study, we have demonstrated that, in patients with IHD and/or CHF taking rate-limiting medications, the means of clinic and ambulatory HRs are numerically similar, but the limits of agreement between them are quite wide. Thus, mean clinic HR may be as much as $14 \mathrm{bpm}$ below or $18 \mathrm{bpm}$ above mean ambulatory $\mathrm{HR}$, depending on the time period examined. These differences are clinically relevant. In the BEAUTIFUL Study, ${ }^{6}$ for instance, a baseline resting HR $\geq 70 \mathrm{bpm}$ was associated with an increased risk of cardiovascular death in patients with stable CAD and left ventricular dysfunction. Furthermore, ivabradine reduced hospital admission for myocardial infarction and coronary revascularisation in the subgroup of patients with an HR $\geq 70 \mathrm{bpm}$. Similarly, in the SHIFT Study, ${ }^{11}$ there was a $16 \%$ increase in the risk of the primary composite end point for every $5 \mathrm{bpm}$ increase in $\mathrm{HR}$ in patients with symptomatic $\mathrm{CHF}$ and an $\mathrm{HR} \geq 70 \mathrm{bpm}$. In the ivabradine group, patients with an $\mathrm{HR}<60 \mathrm{bpm}$ had fewer primary composite end point events during the course of the study. Thus, with well-defined target HRs to aim for in these patients, and with HR changes as little as $5 \mathrm{bpm}$ influencing prognosis, it is likely that the latter will be affected by the method chosen to measure HR - that is, clinic versus ambulatory-given the wide limits of agreement between them, as shown in the present study. As such, clinic and ambulatory HRs cannot be regarded as interchangeable for the assessment of HR control in patients with IHD and/or CHF taking rate-limiting medications.

Whether ambulatory HR is superior to clinic HR for predicting clinical outcomes requires further study. There is evidence that mean $24 \mathrm{~h} \mathrm{HR}$ is more reproducible than clinic HR, at least in hypertensive subjects. ${ }^{21} 22$ However, unlike clinic HR, only limited data exist in support of the utility of $24 \mathrm{~h} \mathrm{HR}$ as a prognostic indicator. Aronow et al, ${ }^{23}$ for example, showed a $14 \%$ increase in the risk of death for each $5 \mathrm{bpm}$ increase in mean $24 \mathrm{~h} \mathrm{HR}$ in a large group of patients with heart disease. Hozawa et $a l^{24}$ found a $17 \%$ increase in the risk of mortality for a $5 \mathrm{bpm}$ increase in home HR in apparently healthy individuals.

Comparative data between clinic and ambulatory HR for predicting adverse clinical outcomes is very scant. The Syst-Eur (Systolic Hypertension in Europe) trial ${ }^{25}$ found a positive relationship between fatal end points and both clinic and $24 \mathrm{~h}$ ambulatory HR, but the latter failed to add any prognostic information over and above that provided by clinic HR. Interestingly, in Syst-Eur, clinic HR was $3.8 \mathrm{bpm}$ higher than average $24 \mathrm{~h}$ HR $(\mathrm{p}<0.001)$, whereas in our study, the two were almost identical. This difference may be due to patients in Syst-Eur being older (mean age 70.2 years), hypertensive, less active, and not taking any rate-limiting medications, features that may increase mean ambulatory $\mathrm{HR}$ relative to resting clinic HR. ${ }^{26}$ By contrast, a recent study by Johansen et al, ${ }^{27}$ examining the prognostic value of different HR measures on clinical outcomes in apparently healthy individuals, demonstrated that night-time HR was a stronger predictor of all-cause mortality than resting $\mathrm{HR}$ or mean $24 \mathrm{~h} \mathrm{HR}$. Of interest, in this study, the mean age of participants (64.4 years) was similar to our patients, but only $5 \%$ were taking a $\beta$-blocker. As a result, all HR measures examined were higher than in our patients $(72.5,75.8$ and $65.9 \mathrm{bpm}$ for resting, $24 \mathrm{~h}$ and night-time $\mathrm{HR}$, respectively). The authors argue that, by removing external influences, including sensory input and physical and mental activities, night-time HR represents a better measure of HR control, hence being a superior predictor of all-cause mortality.

HR is a highly variable parameter which is readily influenced by factors such as posture, ambient temperature, physical activity, mental stress and methodological variables, including period of rest before measurement, who measures it, method and duration of measurement, and the number of readings taken. ${ }^{19}$ If clinic HR is to be used for the assessment of HR control, and

Table 3 Estimates of differences between mean heart rate and limits of agreement at different times

\begin{tabular}{|c|c|c|c|c|c|}
\hline & \multirow[b]{2}{*}{ Mean of differences (SD) } & \multirow[b]{2}{*}{$95 \% \mathrm{Cl}$} & \multirow[b]{2}{*}{$\mathrm{p}$ Value } & \multicolumn{2}{|c|}{ Limits of agreement } \\
\hline & & & & Lower limit & Upper limit \\
\hline Clinic and $24 \mathrm{~h}$ & $0.5(5.7)$ & -1.1 to 2.1 & $=0.54$ & -10.93 & 11.93 \\
\hline Clinic and 09:00-17:00 & $-3.1(5.8)$ & -4.8 to -1.5 & $=0.0003$ & -14.68 & 8.40 \\
\hline Clinic and 07:00-23:00 & $-2.1(5.7)$ & -3.7 to -0.5 & $=0.012$ & -13.58 & 9.34 \\
\hline Clinic and 23:00-07:00 & $3.4(7.4)$ & 1.3 to 5.5 & $=0.0018$ & -11.27 & 18.15 \\
\hline
\end{tabular}




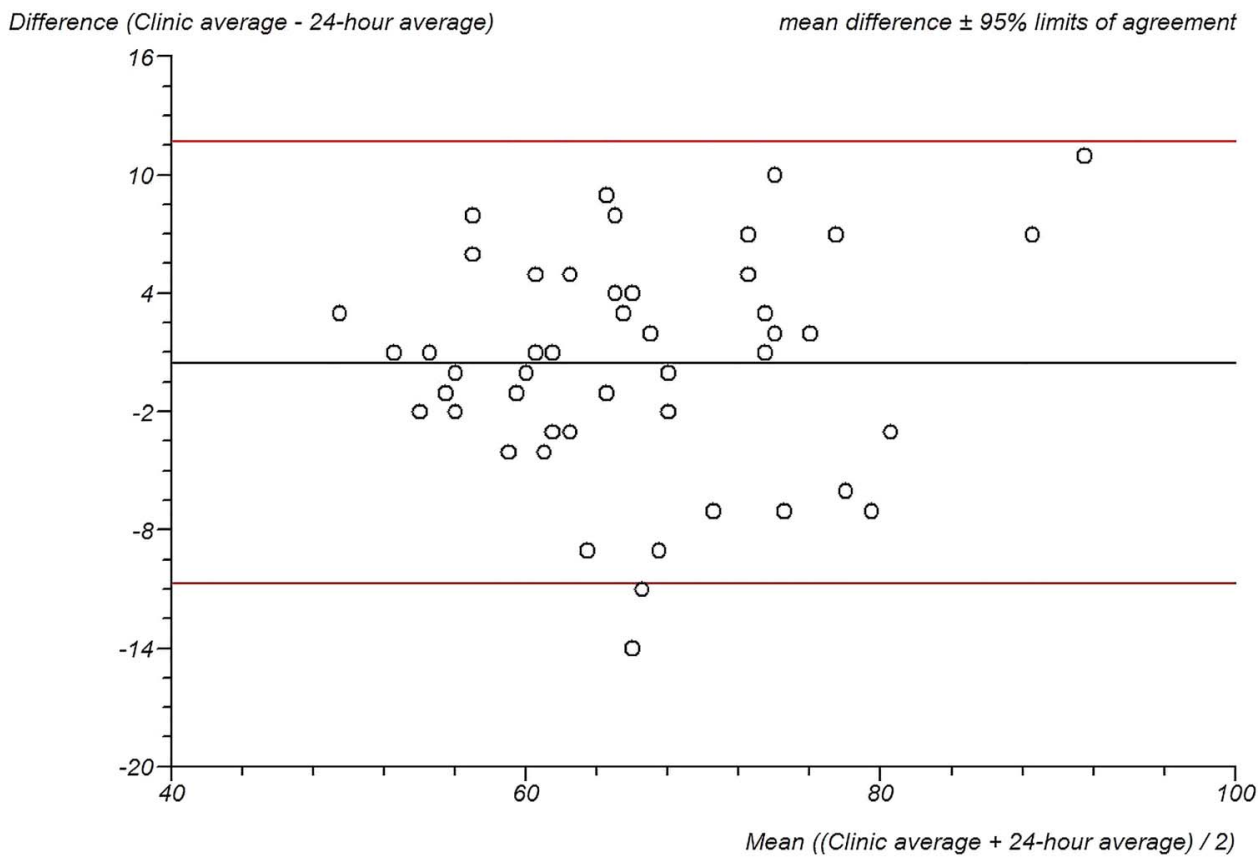

Figure 1 Bland-Altman plot of clinic and $24 \mathrm{~h}$ ambulatory heart rates showing wide limits of agreement between their means.

given our findings of wide limits of agreement between this and mean ambulatory HR, then should its measurement be standardised in a manner similar to that of clinic blood pressure? ${ }^{28}$ HR measurement is poorly standardised in the majority of published literature. $^{29}$ In an attempt to address this issue, the European Society of Hypertension produced a consensus statement on a standardised methodology for measurement of resting $\mathrm{HR},{ }^{30}$ where pulse is palpated during two $30 \mathrm{~s}$ periods, performed in a sitting position, after $5 \mathrm{~min}$ of sitting in a quiet room. According to the consensus panel that drafted these guidelines, the following information should be provided in studies reporting HR data: (1) resting period before measurement; (2) environmental conditions; (3) method of measurement; (4) number of measurements; (5) duration of measurement; (6) body position; (7) nature of the observer. ${ }^{31}$

Finally, the predictive accuracy of a given HR measure for adverse clinical outcomes may be enhanced by coupling it to an index of physical activity. This would allow a distinction to be made between patients who have a high mean HR and a sedentary lifestyle and those who have a high mean HR because of a high level of physical activity. It is well established that a sedentary lifestyle portends poor prognosis, with a doubling of premature death and an increased risk of cardiovascular disease. ${ }^{32}$ An active lifestyle, on the other hand, may extend total life expectancy as well as cardiovascular disease-free life expectancy. ${ }^{33}$ Different methods have been proposed for the assessment of physical activity, including activity questionnaires, activity monitors (pedometers, accelerometers) and indirect calorimetry. $^{33}$

Several limitations to our study are noteworthy. It has a relatively small sample size, but since patients acted as their own controls, the sample size was large enough to enable the detection of statistical differences between the measured variables. Daytime was defined as between 07:00 and 23:00, and nighttime as between 23:00 and 07:00. These timings were set with the assumption that patients would be awake for the majority of the daytime period and asleep for the majority of the night-time period. However, patients' sleep patterns may have varied and so this may not have occurred in all patients. Our findings may not be applicable to other patient groups, including those not taking rate-limiting medications. The latter may have a more 'labile' $24 \mathrm{~h}$ HR profile, with even wider limits of agreement between clinic and ambulatory HR means. Our study does not allow any conclusions to be drawn regarding the superiority of one HR measure over another for predicting adverse clinical outcomes. Adequately powered, prospective, randomised clinical trials would be necessary to answer this question. Furthermore, whether the predictive power of a given ambulatory HR can be enhanced by linking it to a measure of physical activity deserves further study.

\section{Main messages}

- In patients with chronic heart failure and/or ischaemic heart disease taking rate-limiting medications, the mean clinic heart rate is numerically similar to the mean ambulatory heart rates derived from a $24 \mathrm{~h}$ Holter recording.

- The means of clinic and ambulatory heart rates display wide limits of agreement, such that the two measures cannot be regarded as interchangeable.

\section{Current research questions}

- Does the relationship between clinic and ambulatory heart rates demonstrated in this study hold in patients who are not taking rate-limiting medications?

- Is ambulatory heart rate a better predictor of clinical outcomes than clinic heart rate?

- Can the predictive accuracy of ambulatory heart rate for adverse clinical outcomes be enhanced by linking it to a measure of physical activity? 


\section{Key references}

- Fox K, Ford I, Steg PG, et al. Heart rate as a prognostic risk factor in patients with coronary artery disease and left ventricular systolic dysfunction (BEAUTIFUL): a subgroup analysis of a randomised controlled trial. Lancet 2008;372: $817-21$.

- Böhm M, Swedberg K, Komajda M, et al. Heart rate as a risk factor in chronic heart failure (SHIFT): the association between heart rate and outcomes in a randomised placebocontrolled trial. Lancet 2010;376:886-94.

- Valentini M, Parati G. Variables influencing heart rate. Prog Cardiovasc Dis 2009;52:11-19.

- Johansen D, Olsen RH, Pedersen LR, et al. Resting, nighttime, and $24 \mathrm{~h}$ heart rate as markers of cardiovascular risk in middle-aged and elderly men and women with no apparent heart disease. Eur Heart J 2013;34:1732-9.

- Vogel CU, Wolpert C, Wehlind M. How to measure heart rate? Eur J Clin Pharmacol 2004;60:461-6.

Contributors $\mathrm{OJ}, \mathrm{KK}$ and $\mathrm{OE}-\mathrm{O}$ collected the data. SA analysed the data. AS helped with statistics. OJ and ME-O wrote the manuscript. All authors reviewed/ edited the manuscript and contributed to the discussion.

Competing interests None.

Provenance and peer review Not commissioned; externally peer reviewed.

\section{REFERENCES}

1 Jouven X, Empana J-P, Schwartz PJ, et al. Heart-rate profile during exercise as a predictor of sudden death. N Engl J Med 2005;352:1951-8.

2 Benetos $A$, Rudnichi $A$, Thomas $F$, et al. Influence of heart rate on mortality in a French population: Role of age, gender, and blood pressure. Hypertension 1999:33:44-52

3 Pocock SJ, Wang D, Pfeffer MA, et al. Predictors of mortality and morbidity in patients with chronic heart failure. Eur Heart J 2006:27:65-75

4 Braunwald E. Expanding indications for beta-blockers in heart failure. $N$ Eng/ J Med 2001;344:1711-12.

5 Packer M, Coats AJ, Fowler MB, et al. Effect of carvedilol on survival in severe chronic heart failure. N Engl J Med 2001;344:1651-8.

6 Fox K, Ford I, Steg PG, et al. Heart rate as a prognostic risk factor in patients with coronary artery disease and left ventricular systolic dysfunction (BEAUTIFUL): a subgroup analysis of a randomised controlled trial. Lancet 2008;372:817-21.

7 Kjekshus JK. Importance of heart rate in determining beta-blocker efficacy in acute and long-term acute myocardial infarction intervention trials. Am J Cardiol 1986;57:43F-9F.

8 Kjekshus J. Heart rate reduction-a mechanism of benefit? Eur Heart J 1987;8(Suppl L): $115-22$.

9 Kovar D, Cannon CP, Bentley JH, et al. Does initial and delayed heart rate predict mortality in patients with acute coronary syndromes? Clin Cardiol 2004;27:80-6.

10 Palatini $P$, Benetos A, Julius S. Impact of increased heart rate on clinical outcomes in hypertension: implications for antihypertensive drug therapy. Drugs 2006;66:133-44.

11 Swedberg K, Komajda M, Bohm M, et al. Ivabradine and outcomes in chronic heart failure (SHIFT): a randomised placebo-controlled study. Lancet 2010;376:875-85.

12 Böhm M, Swedberg K, Komajda $M$, et al. Heart rate as a risk factor in chronic heart failure (SHIFT): the association between heart rate and outcomes in a randomised placebo-controlled trial. Lancet 2010;376:886-94.
13 Fox K, Ford I, Steg PG, et al. Ivabradine for patients with stable coronary artery disease and left-ventricular systolic dysfunction (BEAUTIFUL): a randomised, double-blind, placebo-controlled trial. Lancet 2008;372:807-16.

14 Reil JC, Böhm M. BEAUTIFUL results-the slower, the better? Lancet 2008;372:779-80.

15 Steg PG, Ferrari R, Ford I, et al. Heart rate and use of beta-blockers in stable outpatients with coronary artery disease. PLOS ONE 2012;7:1-8.

16 McMurray JJ, Adamopoulos S, Anker SD, et al. ESC guidelines for the diagnosis and treatment of acute and chronic heart failure 2012: The Task Force for the Diagnosis and Treatment of Acute and Chronic Heart Failure 2012 of the European Society of Cardiology. Developed in collaboration with the Heart Failure Association (HFA) of the ESC. Eur J Heart Fail 2012;14:803-69.

17 Perk J, De Backer G, Gohlke H, et al. European Guidelines on cardiovascular disease prevention in clinical practice (version 2012). The Fifth Joint Task Force of the European Society of cardiology and other societies on Cardiovascular Disease Prevention in Clinical Practice (constituted by representatives of nine societies and by invited experts). Eur Heart J 2012;33:1635-701.

18 Montalescot $G$, Sechtem U, Achenbach S, et al. ESC guidelines on the management of stable coronary artery disease: the Task Force on the management of stable coronary artery disease of the European Society of Cardiology. Eur Heart $J$ 2013:34:2949-3003.

19 Valentini M, Parati G. Variables influencing heart rate. Prog Cardiovasc Dis 2009;52:11-19.

20 Tardif JC. Heart rate as a treatable cardiovascular risk factor. Br Med Bull 2009:90:71-84.

21 Palatini P, Winnicki M, Santonastaso M, et al. Reproducibility of heart rate measured in the clinic and with 24-hour intermittent recorders. Am J Hypertens 2000;13:92-8.

22 Conway J, Johnston J, Coats A, et al. The use of ambulatory blood pressure monitoring to improve the accuracy and reduce the numbers of subjects in clinical trials of antihypertensive agents. J Hypertens 1988;6:111-6.

23 Aronow WS, Ahn C, Mercando AD, et al. Association of average heart rate on 24-hour ambulatory electrocardiograms with incidence of new coronary events at 48-month follow-up in 1311 patients (mean age 81 years) with heart disease and sinus rhythm. Am J Cardiol 1996;78:1175-6.

24 Hozawa A, Ohkubo T, Kikuya M, et al. Prognostic value of home heart rate for cardiovascular mortality in the general population: the Ohasama study. Am J Hypertens 2004;17:1005-10.

25 Palatini P, Thijs L, Staessen JA, et al. Predictive value of clinic and ambulatory heart rate for mortality in elderly subjects with systolic hypertension. Arch Intern Med 2002;162:2313-21.

26 Mancia G, Parati G, Pomidossi G, et al. Alerting reaction and rise in blood pressure during measurement by physician and nurse. Hypertension 1987;9:209-15.

27 Johansen $\mathrm{D}$, Olsen RH, Pedersen LR, et al. Resting, night-time, and $24 \mathrm{~h}$ heart rate as markers of cardiovascular risk in middle-aged and elderly men and women with no apparent heart disease. Eur Heart J 2013;34:1732-9.

28 O'Brien E, Asmar R, Beilin L, et al. European Society of Hypertension recommendations for conventional, ambulatory and home blood pressure measurement. J Hypertens 2003;21:821-48.

29 Vogel CU, Wolpert C, Wehlind M. How to measure heart rate? Eur J Clin Pharmacol 2004;60:461-6.

30 Palatini P, Benetos A, Grassi G, et al. European Society of Hypertension. Identification and management of the hypertensive patient with elevated heart rate: statement of a European Society of Hypertension Consensus Meeting. I Hypertens 2006;24:603-10

31 Mancia G, De Backer G, Dominiczak A, et al. Guidelines for the management of arterial hypertension (2007) The Task Force for the management of arterial hypertension of the European Society of Hypertension (ESH) and of the European Society of Cardiology (ESC). J Hypertens 2007;25:1105-87.

32 Franco 0 , De Laet C, Peeters $A$, et al. Effects of physical activity on life expectancy with cardiovascular disease. Arch Intern Med 2005;165:2355-60.

33 Graham I, Atar D, Borch-Johnsen K, et al. European guidelines on cardiovascular disease prevention in clinical practice: executive summary. Eur Heart $\mathrm{J}$ 2007;28:2375-414. 